\title{
JÜRGEN M. GEISSINGER
}

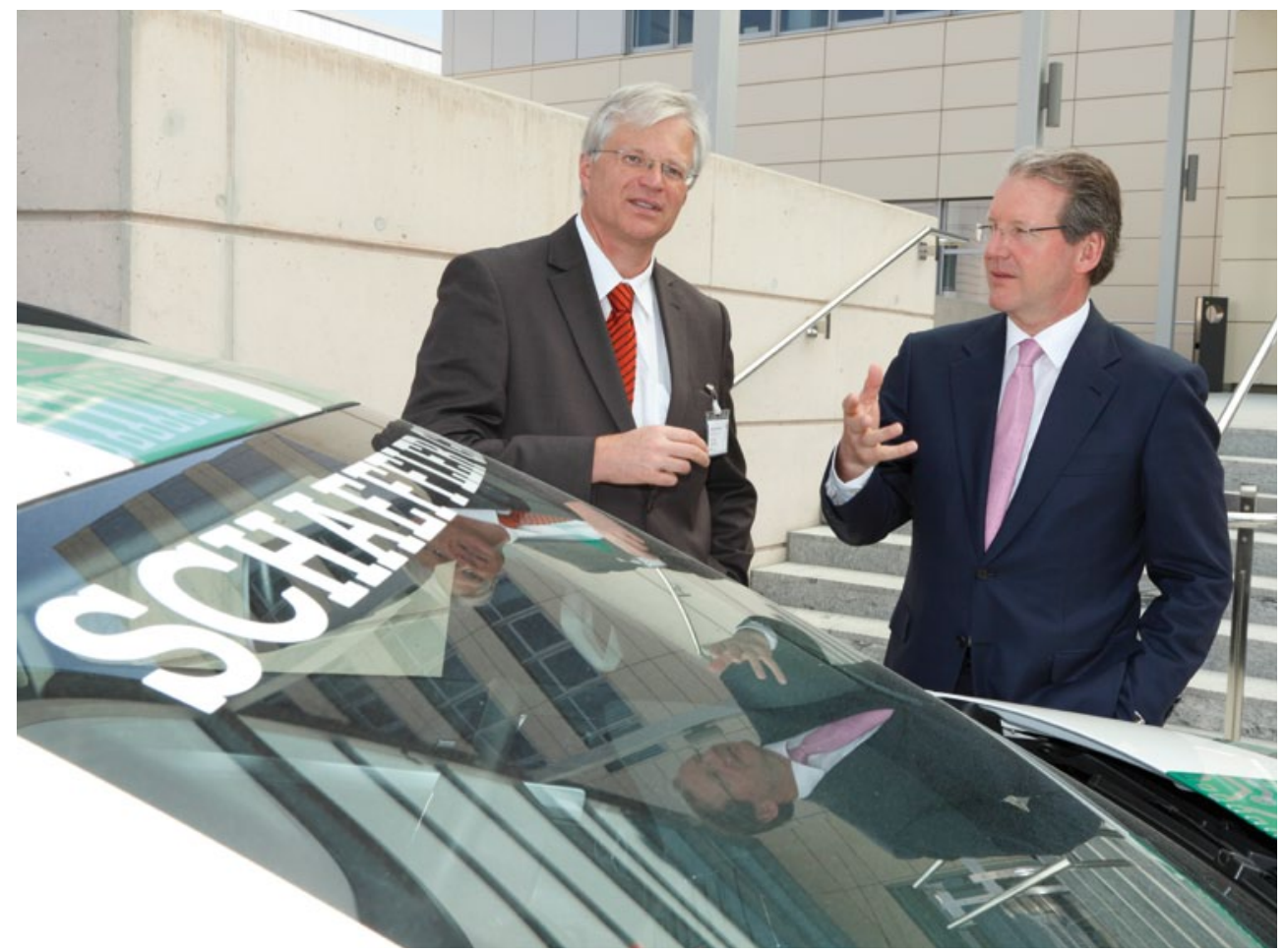

Dr. Jürgen M. Geißinger, Vorsitzender des Vorstands der Schaeffler AG

BILD @ Schaeffler AG

\section{„RICHTUNG UND GRENZEN VORGEBEN“}

Über elf Milliarden Euro Umsatz - viermal so viel wie zu seinem Amtsantritt als CEO bei Schaeffler. Angefangen hat Dr. Jürgen M. Geißinger im fränkischen Herzogenaurach 1998.

Davor stand der Verkauf von ITT Automotive, die spätere ContiTeves, an Continental. Genau zehn Jahre später, im Juli 2008, wagte Schaeffler den Griff nach der Continental AG, von der Schaeffler heute $60 \%$ hält.

Geißinger, geboren 1959, studiert Maschinenbau und promoviert 1989 zum Dr.-Ing. Er liebt die Geschwindigkeit, geschäftlich und privat. 1992 steigt er bei ITT Automotive ein und avanciert bereits 1997 zum Vorsitzenden der Geschäftsführung. Ein Jahr später folgt der Verkauf an Conti und Geißingers Wechsel als Vorsitzender der Geschäftsleitung zur INA-Holding Schaeffler KG, der konzernführenden Gesellschaft der Schaeffler Gruppe.

Unter seiner Leitung stieg der Umsatz der Gruppe um ein Mehrfaches. Als ehemaligem Handballtrainer ist Geißinger klar, dass der Erfolg nicht alleine ihm zu verdanken ist. „Das geht nur mit einem motivierten und professionellen Team. Die Aufgabe von mir, als Trainer, besteht darin, die einzelnen Individuen so zu entwickeln und einzusetzen, dass für das gesamte Ganze etwas Großes herauskommt. Gemeinsam definieren wir die Ziele“, erklärt Geißinger seine Mission, „die Richtung und die Grenzen muss ich dann aber schon von Zeit zu Zeit vorgeben."

\section{„ICH WÜRDE ALLES WIEDER SO MACHEN“}

Geißinger ist begeisterter Techniker, kein Wunder, lebt er doch im ehemaligen Wohnhaus von Felix Wankel am Bodensee. Dort schläft man mit den Gedanken an Technik ein und wacht mit guten Ideen auf. Und Perfektionist ist er. „Im Privaten wird das nicht immer nur geschätzt“, erklärt er schmunzelnd. Hier blitzt der Mensch im CEO durch. Er hat Humor, einen ganz eigenen. Und einen eigenen Kopf hat er auch, das hat er mit der inzwischen lebendigen und fruchtbaren Conti-Kooperation bewiesen. „Wir würden alles wieder so machen“, meint Geißinger dazu. Auf die Frage, worauf er in den letzten fünf Jahren gerne verzichtet hätte, antwortet er nicht etwa, die schlechte Presse im Zuge des Kaufs der Conti-Anteile, sondern: „Auf meine im Januar beim Skifahren gebrochene Schulter." Verzichtet hätte er sicher gerne auf Rang 233 bei der diesjährigen Mille Miglia: „Nächstes Jahr sind wir besser.“ An der „schönsten Rallye der Welt“ nahm Geißinger in einem Mercedes 300 SL teil. Einen dieser legendären Wagen nennt er, als Cabrio und in Taubenblau, sein eigen - zusätzlich zum 911, einem VW Bus und einer BMW S 1000 RR.

Geißinger galt schon zu ITT-Zeiten als rustikaler Unternehmenslenker, die soll es auch woanders geben und häufig sind sie erfolgreich. Sein Erfolg spricht für ihn und ab heute ist auch klar: Hinter der rauen Schale liegt ein aufrechter Kern. Maria-Elisabeth Schaeffler schätzt dies - und Sie, werte Leser, wissen es. 